\title{
UNA CONVERSACIÓN INTERMINABLE (Comentario sobre los amistosos comentarios de nuestros colegas)
}

\author{
Liborio L. Hierro \\ Universidad Autónoma de Madrid
}

\section{PRIMEROS AGRADECIMIENTOS}

\begin{abstract}
engo que empezar con tres cuestiones previas. La primera es agradecer a mis compañeras y compañeros del Área de Filosofía del Derecho de la Universidad Autónoma de Madrid la organización de esta publicación, que tuvo su germen en una intensa jornada celebrada allí el 25 de noviembre de 2016, y agradecer también a los editores de la revista Doxa, Cuadernos de Filosofía del Derecho su acogida. Parte de este texto recoge lo que dije en aquella jornada. Un agradecimiento especial tengo para Alfonso RUIZ MiguEL que ha encabezado esta iniciativa y ha escrito su muy amable presentación. Debería decir que no merezco esta atención, este homenaje compartido con Francisco LAPORTA, pero no pienso decirlo porque, merecida o inmerecida, me satisface profundamente y mi agradecimiento es infinito. La segunda es, naturalmente, expresar mi agradecimiento a todas las compañeras y a todos los compañeros que participan en esta publicación, muchos de los cuales lo hicieron ya en aquella reunión; agradecer que hayan dedicado una parte de su tiempo y de su atención a comentar algún aspecto de lo que nosotros hemos tratado de aportar, durante los años de actividad académica, a la filosofía del derecho. También esto me provoca una inmensa gratitud. La tercera, finalmente, es que deseo unirme con todos los demás al homenaje que Francisco LAPORTA se merece y ahora le brindamos. Sobre esto me extenderé un poco.
\end{abstract}

\section{HOMENAJE A FRANCISCO LAPORTA}

La coincidencia de que Paco y yo nos jubilemos en el mismo curso académico no debe oscurecer la realidad de que Paco es mayor que yo en edad y en saber (el gobierno no es, a los efectos académicos, cuestión relevante). Paco nació el año anterior al que yo nací. Él es del 45 y yo soy del 46. Tratará él de alegar que solo nos separan cincuenta y cinco días, y eso es verdad, pero no conseguirá eludir que pertenecemos a dos ejercicios fiscales distintos. Menos discutible es, en todo caso, que Paco es mayor que yo en saber. Y ahora hablo ya en serio. No es lo más frecuente que una persona con la que has seguido un recorrido intelectual coincidente en el tiempo, coincidente en el 
espacio y coincidente en los temas, resulte ser no solo un compañero sino un maestro, y Paco LAPORTA ha sido para mí un maestro, uno de mis maestros. Paco, como todos reconocemos, tiene una singular capacidad de análisis y una excepcional brillantez en la expresión. Hubiera sido imposible, al menos para mí, desarrollar el concepto de libertad o el concepto de igualdad sin partir de sus trabajos de 1983 y 1985; he tratado de discrepar parcialmente de su defensa del imperio de la ley, pero ineludiblemente tomando como referencia su trabajo de 1994, que se ha traducido luego en su impresionante «obra grande» de 2007; discrepo, por otra parte, de su concepto de los derechos humanos pero es imposible hacerlo sin referirse a su trabajo de 1987; y no podría haber explicado —o tratado de explicar — las ventajas de ser positivista sin su vindicación del observador crítico de 1990 . No me es posible escribir sobre todo ello pues, escribiendo ahora como un participante más, debo guardar la misma moderación que a todos se les ha pedido, así que me limitaré a una mínima observación sobre la obra de Paco. Creo que lo que compartimos es precisamente aquello: la defensa del observador crítico como posición filosófica; un observador que participa y, por eso, critica; un participante que observa y, por eso, analiza.

Casi todos los que en esta publicación se ocupan de su obra discuten su concepto de los derechos humanos o, en mayor número, diversos aspectos del imperio de la ley. Son, sin duda, los aspectos más influyentes de su obra. Quiero, sin embargo, llamar la atención sobre un conjunto de aportaciones de LAPORTA sobre las relaciones entre el derecho y la moral que reunió en un libro publicado en Fontamara en 1993 y sin cuya influencia no hubiera podido escribir yo ¿Por qué ser positivista? Se recogen allí un trabajo largo que había publicado previamente en la Historia de la Ética, editada por Victoria CAMPS en 1989, y otros tres más cortos, todos ellos ya publicados en 1990. Al principio Paco afirma que «el problema de las relaciones entre el derecho y la moral no es un tema de la filosofía del derecho, sino que es el lugar donde la filosofía del derecho está»». Creo sinceramente que es un libro magnífico. Un libro que se sitúa en la misma órbita y a la misma altura que la conocida conferencia de Herbert HART de 1957, El positivismo jurídico y la separación entre el derecho y la moral, el artículo de Alf Ross de 1961, El concepto de validez y el conflicto entre el positivismo jurídico y el derecho natural, o el libro de David Lyons Ética y derecho, de 1984. Para mí es, como estos, un clásico, aunque tiene, frente a ellos, la limitación de estar escrito por un español en castellano, con lo que es desconocido para los anglohablantes y mucho me temo que, lamentablemente por la misma razón, para muchos hispanoparlantes. Pero no dudo de que es un clásico.

Mantiene Paco allí que el que haya normas morales con vigencia en un sistema jurídico no se debe a su propio carácter moral sino a que alguna norma jurídica de ese sistema la ha incorporado o se ha remitido a ella y —afirma- «esa precaución permite mantener al mismo tiempo la idea de que no hay conexión necesaria entre el derecho y la moral, y la idea de que, a pesar de ello, las normas jurídicas de los ordenamientos modernos están con frecuencia fuertemente penetradas de contenido moral» (1993: 61). Esto es lo que HART hubiera llamado una «elemental doctrina» (1962: 12). Mientras que HART indaga los antecedentes de esa elemental doctrina, que remonta a BENTHAM y AUSTin, con la pretensión principal de aclarar qué es el positivismo, LAPORTA la utiliza para analizar los problemas que suscita el cruce de estos dos órdenes 
normativos diferentes: la legalización de la moral y la moralización del derecho. A pesar de sostener la tesis de la separación, Paco señala allí que «hay también algunos componentes morales que son de tal naturaleza que si el sistema jurídico los ignora entonces corre el peligro de perder su propia identidad como sistema jurídico, es decir, corre el riesgo de dejar de ser una empresa cuyo propósito es someter la conducta humana a normas» (1993: 29) y cita los ocho requisitos de FuLLER. Allí estaba plantada la semilla de su libro El imperio de la ley. Ello no obstante, Paco subraya allí que «nuestro problema, si tiene solución, la tiene solo en relación con el derecho «justo» y que, por ello, tenemos que pasar de la esfera de la legalidad y penetrar «necesariamente en el territorio de la legitimidad» (1993: 73) para concluir que la legitimación del derecho (esto es, la mera creencia mayoritaria en su legitimidad) como mecanismo organizativo solo tiene un valor instrumental, que el origen democrático de las normas jurídicas no es condición suficiente de su justicia y que los derechos humanos constituyen el criterio de legitimidad — «que no es, por cierto, incompatible con los dos anteriores»-que se impone hoy con mayor fuerza (1993: 77, 82 y 84).

Mi discrepancia con Paco, ligera discrepancia, en torno al imperio de la ley consiste en incorporar su legitimación en origen — su carácter democrático- como un elemento que refuerza su carácter moral; en mis propias palabras: «Esta idea del "imperio de la ley" como exigencia ética admite, sin embargo, dos interpretaciones, una débil y una fuerte. A la primera la denomino "interpretación débil" porque exige menos elementos cualificadores ya que prescinde de cuál sea el origen de la ley... Sin negar en absoluto la dimensión ética que esta tesis más débil implica, creo por mi parte que una "interpretación fuerte", como lo es la de Elías DíAz, que introduce en la noción misma de "imperio de la ley" el elemento democrático, resulta necesaria, bajo ese mismo punto de vista ético, para dotar de un fundamento sólido a la pretensión moral de obediencia a la ley (y, en caso contrario, para justificar moralmente su desobediencia)... La tesis débil parece seguir defendiendo la superioridad moral de la legalidad frente a la arbitrariedad, lo cual no parece estar hoy en cuestión; la tesis fuerte parece seguir defendiendo la superioridad moral de la voluntad general (democracia) frente a cualquier forma de autoritarismo (tiranía u oligarquía), lo que todavía está, desgraciadamente, en cuestión» (HIERRO, 1998: 21).

Nuestra defensa del imperio de la ley y, con las mencionadas discrepancias, de su carácter moral hace que una gran parte de los comentarios nos incluya en lo que hoy se viene denominando positivismo normativo (WALDRON), positivismo prescriptivo (CAMPBELL) e incluso positivismo ético.

\section{DE NUEVO SOBRE EL POSITIVISMO}

La primera parece ser la cuestión de la etiqueta. ¿Suscribimos un positivismo normativo o nos mantenemos en un positivismo metodológico? ¿Coincidimos con el positivismo excluyente de RAZ o más bien nos situamos en el positivismo presuntivo de SCHAUER? O bien — como denuncia Pep Aguiló— ¿sufrimos una radical ambigüedad? O mejor — como pregunta Miguel Ángel RoDILlA— ¿por qué seguir insistiendo en auto-etiquetarse? 
De acuerdo: lo importante no es la etiqueta que, además, se ha complicado mucho; pero yo no escribí «¿por qué llamarse positivista?», lo que escribí fue «¿por qué ser positivista?» (2002), así que me parece más útil enunciar mis convicciones tratando de responder, al mismo tiempo, a algunas de las cuestiones planteadas ${ }^{1}$, y dejar que sean los demás los que, si procede, me pongan finalmente la etiqueta.

(1) El derecho tiene una relación necesaria con la moralidad positiva. Todo sistema jurídico incluye entre sus normas alguna creencia y/o regla de la moralidad positiva de la sociedad o de la de alguna persona o grupo de personas de la sociedad, y no puede existir en una sociedad un sistema jurídico sin que exista alguna creencia y/o regla de la moralidad positiva de esa sociedad o de alguna persona o grupo de personas de esa sociedad que establezca la obligación moral (ya sea prima facie ya sea absoluta) de obedecer aquellas normas jurídicas (RoDILLA).

(2) El derecho tiene una relación contingente con la moralidad crítica: la coincidencia entre las normas jurídicas y las normas de una moral crítica es meramente contingente y solo puede establecerse desde un punto de vista moral, y no desde un punto de vista jurídico; la obligación moral de obedecer las normas jurídicas es asimismo contingente y solo puede establecerse, asimismo, desde un punto de vista moral, y no desde un punto de vista jurídico. Admito que es difícil suponer algún sistema jurídico que exista o haya existido que no incluya ninguna norma con la que un participanteno-aceptante o un observador crítico no esté moralmente conforme, es decir que no incluya entre sus normas ninguna creencia y/o regla de la moral que él acepta. Lo relevante es, en este aspecto, que esta coincidencia es meramente contingente y no conceptualmente necesaria. No es la existencia de ese sistema jurídico como tal sistema jurídico la razón de que todas, muchas o algunas de sus normas resulten moralmente aceptables bajo un punto de vista crítico; la razón sería una razón exclusivamente moral (RoDilla).

(3) Una cuestión distinta es afirmar que la función que la tesis de la separación desempeñó para superar la concepción iusnaturalista del derecho ha perdido hoy importancia y, por el contrario, la ha adquirido la cuestión de si puede afirmarse una obligación moral prima facie de obedecer las normas jurídicas de un sistema jurídico civilizado. La respuesta afirmativa es, obviamente, una tesis moral normativa que, en términos muy generales, suscribo. Pero suscribir esta tesis moral no implica, en ningún caso, renunciar a la tesis de la separación (Aguiló, AtienZA).

(4) Es posible identificar el significado de una regla jurídica y la ponderación de valores subyacente a ella sin estar de acuerdo con el significado de la regla ni con la ponderación subyacente, y reconocer que es jurídicamente válida (AGUILÓ).

(5) Ser leal a una regla jurídica es ser leal a su enunciado, a la ponderación subyacente a ese enunciado y a la autoridad legítima para hacer esa ponderación, sin perjuicio de reconocer que, a veces, el enunciado y/o la ponderación subyacente no permite una subsunción clara del caso y el que tiene que decidir ha de elaborar una interpretación

1 Como supongo que no dispondremos de pruebas de imprenta, me referiré genéricamente entre paréntesis a la autora o el autor que, principalmente, me ha sugerido en este debate la cuestión que comento o trato de responder. 
entre varias posibles alternativas por lo que tiene una discrecionalidad débil. Si el juez solo tuviera que ser leal a la ponderación subyacente, entonces sobraría la autoridad que formula la regla. Una consecuencia no menor es que, en tal caso, se abandonaría todo intento de generalidad y se debilitaría la previsibilidad (AguiLó, MORESO).

(6) La previsibilidad más valiosa no es solo la previsibilidad por sí misma sino la de expectativas legítimas, pero eso no implica que la previsibilidad no esté vinculada también a rasgos formales y que la previsibilidad por sí misma no revista también un valor instrumental ${ }^{2}$ (LIFANTE, MARCILLA). Isabel LIFANTE sostiene que no son las reglas, ya que es imposible conocer al detalle todo el derecho, sino el reconocimiento de los principios que subyacen a ellas lo que permite orientarse a la población en general. Dudo que esta afirmación resista un análisis histórico o empírico; parafraseando a James MADISON diría «if men were angels, no rules would be necessary» ${ }^{3}$. Pero no somos ángeles.

(7) En consecuencia me parece que el modelo interpretativo-aplicativo más correcto al sistema constitucional es, como indica MORESO siguiendo a BAYÓN, una jurisprudencia de razones con reglas o de reglas con defeaters. Esto no tiene por qué suponer un mayor activismo judicial, sino una interpretación y aplicación más atenta al espíritu y finalidad de las leyes, a la realidad social del tiempo en que han de ser aplicadas y a su inserción en el orden constitucional. Y me atrevo a añadir dos cosas: en primer lugar, que cuando la ponderación subyacente a una regla es clara y no contradice normas superiores (estén formuladas como reglas o como principios), incluidas las constitucionales, entonces el juez no tiene que hacer la mejor ponderación; debe atenerse a la ponderación ya hecha por el legislador. En segundo lugar, que el defeater solo entra en juego en los casos recalcitrantes (Aguiló, Moreso, MARCILLA). Sostiene Pep Aguiló, en este contexto, que el voto particular es la prueba de que solo hay una respuesta correcta — presupone esta tesis, dice textualmente-, afirmación que me resulta muy contra-intuitiva; más bien parece que la posibilidad de votos particulares o disidentes presuponen que hay varias interpretaciones posibles y plausibles de las normas aplicables al caso.

(8) Nuestro punto de vista- me refiero al que en estos aspectos compartimos Paco LAPORTA y yo- implica, desde luego, una especial atención a la legislación y no desplaza el protagonismo jurídico a la jurisdicción. Escribí hace tiempo que en el estado constitucional de derecho, «lo que nos importa es que las leyes sean expresión de la voluntad general y, por ello, que en cada escalón de la constitución o desenvolvimiento de las comunidades políticas, las decisiones normativas estén originariamente legitimadas democráticamente. Una soberanía escalonada sigue siendo un ejercicio colectivo de la libertad negativa mediante las técnicas de instrumentación de la libertad positiva. Una Constitución es un momento del pacto social, pero un momento muy limitado, y el pacto social solo puede ser una realidad actuante en la medida en que se actualiza mediante la legislación» (HIERRO, 1998: 43). La división de poderes no supone que los

2 Dice E. DíAz: «el Derecho proporciona al menos la seguridad mínima de poder saber con certeza lo que está prohibido y lo que está permitido. Y eso es siempre mejor, creo, que la total arbitrariedad o la absoluta inseguridad del no-Derecho» (1980: 41).

${ }^{3}$ La conocida frase de MADISON fue: «If men were angels, no government would be necessary». 
tres poderes son iguales y simétricos, supone solo que funcionan con independencia orgánica y funcional, mediante un cierto sistema de controles y equilibrios, para garantizar, precisamente, el gobierno de las leyes sobre el gobierno de los hombres, esto es: el imperio de la ley. El legislativo, en este sentido, no es el todo y la parte; en la creación de la ley, es un poder superior a los otros dos (AlmOguera, que suscita la aparente contradicción del legislador como todo y como parte; ALEMANY, que explica muy bien nuestra idea del «mal que más tememos» —el desplazamiento del protagonismo desde la legislación a la jurisdicción - para declarar, un tanto apodícticamente, que nuestro punto de vista ha sido desbordado por la historia; y CuEvA, que básicamente coincide con nuestro punto de vista aunque señala algunas insuficiencias del modelo vigente).

(9) Termino esta parte. Dije antes que dejaba a los demás poner la etiqueta, pero no eludiré pronunciarme sobre ello. Utilizando aquella vieja pero clara distinción de BoBBIO, que ha quedado de nuevo oscurecida por la escolástica anglosajona, creo que soy positivista como posición metodológica porque creo que la relación entre el derecho y la moral es frecuente y extensa pero es contingente. Creo que no soy positivista como posición teórica porque no creo que el ordenamiento jurídico sea siempre, ni siquiera con frecuencia, pleno y coherente, y creo que la interpretación y aplicación del derecho es una tarea complicada y no una mera deducción lógica, y creo que no hay, en muchos casos, una única respuesta correcta. Y no soy positivista como posición ética porque no creo que el ordenamiento jurídico merezca siempre ni merezca todo él una obediencia moral.

Y no veo contradicción alguna en afirmar la separación conceptual —solo conceptual - entre el derecho y la moral, y pretender al mismo tiempo que el derecho realice ciertos ideales morales, no todos, por supuesto, pero sí algunos muy relevantes como son los que se expresan en los derechos humanos. Y si desear un orden jurídico que traduzca mediante procedimientos democráticos esos valores en normas claras, estables y eficaces, a las que los jueces deben una especial lealtad, si esto es positivismo normativo, entonces también soy positivista normativo.

\section{TRES CUESTIONES CONEXAS}

Se han suscitado también tres cuestiones que, según creo, tienen una estrecha conexión con ese enfoque que sostengo, positivista en sentido metodológico, moderadamente realista en el plano de la teoría del derecho y abiertamente liberal-igualitario (socialdemócrata, decimos en Europa) en la fundamentación moral del orden políticojurídico. La primera, la más general, se refiere a la relación de la libertad negativa con la libertad positiva que yo argumento como base de la justificación moral de las decisiones democráticas (RUIZ MigUEL); la segunda, estrechamente relacionada con aquella, suscita la cuestión de la reforma constitucional en el diseño de la Constitución Española (ESCUDERO); la tercera, más concreta y distante pero conexa, se refiere a la deontología de las profesiones jurídicas (LA TORRE, MALEM, Vilajosana).

(1) Solía explicar a mis alumnos que cuando yo era joven la organización de un día de excursión a la montaña requería, entre otros acuerdos como los relativos a la fecha, el lugar o el transporte, la decisión sobre qué música había que llevar. La simple 
razón es que no era posible o conveniente llevar más de un aparato de reproducción (un pickup) dado su peso y tamaño, ni una cantidad excesiva de discos (vinilos) por idéntica razón; hoy día a nadie se le ocurriría pensar que, dada la infinidad de piezas que cada cual puede cargar en su dispositivo de reproducción y el tamaño y peso de estos, se requiera una decisión colectiva para determinar la música disponible en la excursión. El problema — como plantea RuIZ MigUEL — aparece cuando lo que está en cuestión es precisamente si algo requiere o no requiere una decisión interdependiente. $¿$ Es el culto religioso un asunto colectivo, como tantos pensaron incluso después de la Reforma? ¿Son las relaciones sexuales un asunto colectivo, como se ha pensado hasta muy recientemente y todavía se piensa en muchos contextos culturales? El debate sobre la imposición jurídica de la moralidad positiva que sostuvieron HART y DEVLIN era precisamente un debate sobre esta cuestión, debate que, por otra parte, es el mismo que se suscita sobre qué está dentro y qué está fuera del coto vedado. Mi respuesta al problema es clara: cuando no hay acuerdo, la decisión corresponde a la mayoría y si la mayoría se mantiene cerrilmente aferrada a la tradición y decide continuar imponiendo - digamos - sus criterios musicales al conjunto de excursionistas, o sus criterios religiosos al conjunto de ciudadanos, lo único que yo puedo y debo exigir es que se mantenga abierto el debate para convencer a otros de su error y generar una nueva mayoría. Rousseau tenía razón (Ruiz MigueL).

(2) El problema de la reforma constitucional en España no deja de ser una buena aplicación práctica del anterior. Al fin y al cabo la sentencia 31/2010, de 28 de junio, del Tribunal Constitucional constituyó un supuesto claro de decisión contra-mayoritaria. El Estatuto de Cataluña había sido aprobado, tras una tramitación correcta, por todas las instancias democráticas lo que incluía al Parlamento Catalán (30 de septiembre de 2005) y al Parlamento Español (el Congreso el 30 de marzo y el Senado el 10 de mayo de 2006) así como al pueblo de Cataluña en referéndum (el 18 de junio de 2006). Un ejemplo nítido de lo que en otro momento consideré un problema frecuente: «atribuir la última palabra a la mayoría de los miembros de un tribunal y, al mismo tiempo, poner serias dificultades al cambio de una constitución son dos medidas institucionales que conjuntamente - y sean cuales sean las buenas razones que pueden apoyar a la una y a la otra-bloquean cualquier solución a lo que puede ser la situación más frecuente: que la mayoría legislativa no esté en desacuerdo con lo que dice la Constitución sino que esté en desacuerdo con lo que la mayoría de los miembros del Tribunal Constitucional dicen que dice la Constitución» (HIERRO, 2016: 195). Por eso, he defendido que una reforma de nuestra Constitución debiera incluir una reforma de los arts. 167 y 168 para establecer un único sistema de reforma menos rígido que el previsto en el 168, que resulta prácticamente una cláusula de intangibilidad. Mientas tanto me inclino por una deferencia fuerte hacia el legislador: «allí donde la Constitución admite cualquier margen de interpretación, cualquier alternativa racional es constitucional» (ibid., 203). Lo que implica, desde luego, una interpretación restrictiva del 168 y una interpretación extensiva del 167 (ESCUDERO, que me sorprende al defender una interpretación rigurosa y no restrictiva del 168).

(3) Siempre he pensado que la enseñanza del derecho debería incluir la enseñanza de la deontología de las profesiones jurídicas (VILAJOSANA, con gran coincidencia) y que esta disciplina requiere una reconstrucción teórica y una justificación moral del 
rol de cada profesión y de su organización institucional. La deontología construida por los propios profesionales y solo por ellos resulta un enmascaramiento moral. Reiteradamente he tratado, sin mucho éxito, de hacer un desenmascaramiento de ese tipo de deontología construida exclusivamente desde dentro de las profesiones. Discusiones que he mantenido en público con Manuel ATIENZA y con Massimo LA TORRE, y las aportaciones sobre el tema en esta ocasión (MALEM, VILAJOSANA y LA TORRE) ponen de relieve mi escasa capacidad de convicción. Me viene a la memoria lo que FERRAJOLI decía en ocasión similar: «Esperaba las críticas, mucho menos las incomprensiones» (FERRAJOLI, 2012: 309). Quiero pensar que es mi afán por desenmascarar las frecuentes mixtificaciones del «alma de la toga» lo que me ha hecho marginar la defensa del compromiso público del abogado. Creo que, en efecto, ello forma parte de la reconstrucción teórica y la justificación moral del rol profesional y de su organización institucional, pero sin duda requiere mayor atención.

\section{INTERLUDIO SOBRE LA HISTORIA DE LA FILOSOFÍA Y LA APORTACIÓN DE LOS CLÁSICOS}

Me queda, de momento, una cuestión un tanto transversal a la teoría del derecho y a la teoría de la justicia. Se trata del diálogo con los clásicos al que se refiere Julián SAUQUILLO. Cuando me enfrenté por primera vez al estudio del entonces llamado «Derecho Natural», en el primer curso de mi licenciatura allá por el curso 1963-1964, se me hizo adquirir y estudiar un libro sobre «Los griegos y el derecho natural». El tema y el libro me parecieron horribles. Ello no obstante venía bastante bien equipado del Instituto Ramiro de Maeztu donde Luis Ortiz MuÑOZ, Antonio MAGARiÑOS, Jaime OLIVER Asín y Manuel Mindán MANERO me habían enseñado a amar a los clásicos en las lenguas, en la literatura y en la filosofía. Cuando cinco años después, terminada la carrera, me incorporé a la cátedra de filosofía del derecho de Joaquín RuIZ GimÉNEZ había adquirido una firme animadversión a convertir la filosofía en historia de la filosofía, lo que era tan frecuente. Me parece que me influyeron, sobre todo, el librito de Manuel SACRISTÁN Sobre el lugar de la filosofía en los estudios superiores (1968) y los Ensayos filosóficos de Bertrand Rusell (1968); años más tarde Norberto BOBBIO me confirmaría en la idea de que la historia de cada idea hay que archivarla en el cajón de la idea y no en el cajón de la historia. Es cierto lo que SAUQUILLO dice que le contó Alfonso RUIZ Miguel: que todas las mañanas yo solía dedicar la primera media hora de mi jornada a leer a los clásicos. Luego los he utilizado como he podido, con temor y con respeto, pero - como Julián dice - nunca como argumento central. Con la mayor frecuencia lo que he experimentado es la abrumadora sensación de que, en nuestras discusiones, casi todo está ya dicho y lo único que nos cabe es volver a formular los mismos problemas para tratar de encontrar nuevas soluciones.

\section{SOBRE FILOSOFÍA POLÍTICA Y DERECHOS HUMANOS}

Me atrevo a sugerir que la distinción operativa que los organizadores hicieron al distribuir el seminario del 25 de noviembre en dos sesiones, de mañana y de tarde, de- 
dicadas una a la teoría del derecho y otra a la filosofía política fue muy oportuna para poner de relieve que sostener, en el nivel epistemológico, un positivismo metodológico y sostener, en el nivel ontológico, un positivismo normativo (el ideal de un derecho de reglas claras hasta donde ello es posible) no implica - ni la una ni la otra ni ambas tesis juntas - caer en el positivismo ético. Tanto LAPORTA como yo hemos dedicado una buena parte de nuestra atención a los derechos humanos como contenido ideal de un derecho justo. Algo, por otra parte, que también hicieron positivistas recalcitrantes como Ross, HART o BOBBIO, entre otros muchos, defendiendo abiertamente la dignidad de la persona, la libertad y la democracia en momentos de grandes turbulencias filosóficas y políticas.

(1) Manuel ATIENZA se pregunta, nos pregunta, cómo es compatible la concepción de los derechos humanos como bienes morales con la tesis de la separación y con la constatación del papel que desempeñan como valores morales en nuestros sistemas jurídicos. La tesis de la separación solo dice que la presencia de valores morales, unos u otros, en los sistemas jurídicos es contingente. No veo el problema. Salvo que me digan que la ley que impone la pena de muerte en el estado de Texas no es una ley, porque si fuera una ley no impondría la pena de muerte, o que las normas jurídicas que discriminan a la mujer en Arabia Saudí no son normas jurídicas, porque si lo fueran no discriminarían a la mujer. No serían leyes sino corrupciones de las leyes. Una vieja afirmación que no conduce a ninguna parte y que, naturalmente, no es la que Manolo quiere hacer. Quizás Manolo quiere decir, como dice Ronald DwORKIN, que la citada ley de Texas es contraria a la Constitución de los Estados Unidos correctamente interpretada conforme a los principios que ella misma contiene. DwORKIN llega a sostener que, por tanto, es inválida, pero desafortunadamente los sistemas jurídicos no incluyen entre sus órganos superiores de adjudicación a los filósofos del derecho por lo que la ley de Texas tiene toda la pinta de ser una ley desafortunadamente válida en Texas. Pasemos al contenido moral de los derechos humanos.

(2) Con algunos de los participantes ya he discutido muchas veces en qué medida me parece coherente el no cognoscitivismo meta-ético con la defensa de los derechos humanos. Creo que, como ya he escrito, «el único axioma moral que la teoría de los derechos requiere y utiliza es el de que la persona, como agente autónomo, es el sujeto de la moralidad y de que cualquier persona vale moralmente igual. Esta concepción moral de la persona encuentra un fundamento sólidamente razonable en cuanto es el requisito mismo del razonamiento moral y sirve como fundamento necesario, suficiente y unitario de los derechos humanos cuando estos son entendidos como las situaciones normativas que constituyen condición necesaria para que la persona se desenvuelva como agente moral en su contexto» (2016:55).

Los no cognoscitivistas no somos necesariamente relativistas. Afirmaciones como la que acabo de hacer son afirmaciones objetivas, no en el sentido de que describan algo que existe en un mundo real externo a nosotros, pero sí en el sentido de expresar las mejores razones y que, por ello, cualquier persona abierta a un debate moral racional podría y debería aceptar si no es capaz de ofrecer mejores razones en contra. Afortunadamente en el mundo de hoy, bastante lamentable desde el punto de vista de la justicia, hay sin embargo un cierto consenso filosófico-político sobre los derechos humanos y, en efecto, juegan un papel central en algunos de nuestros ordenamientos 
jurídicos. Hasta aquí no veo ningún problema y con frecuencia tengo la impresión de que sostenemos desacuerdos meramente verbales.

(3) Los problemas aparecen en la teoría normativa del derecho que esta presencia implica. Es decir, en cuál es el modo de interpretar y aplicar el derecho cuando están presentes los derechos humanos en sus normas superiores, las normas constitucionales. Eso tiene mucho que ver con la discusión sobre la teoría del derecho o, mejor dicho, sobre la meta-teoría. Como he tratado de señalar, parece que LAPORTA y yo somos positivistas en ese sentido que ahora se ha dado en llamar normativo y que SCHAUER llama presuntivo, y que MORESO ha resumido tan correctamente. Ahí nos llaman positivistas porque defendemos el imperio de la ley y el principio democrático frente al imperio de los principios y el activismo judicial. Pero no lo hacemos porque despreciemos los derechos humanos como ideal moral frente a los derechos constitucionales como realidad jurídico-positiva, sino que lo hacemos porque creemos que el imperio de la ley y el principio democrático son mejores instrumentos para la positivación de aquellos ideales, los derechos humanos.

(4) Eusebio FERNÁNDEZ y Ángeles RÓDENAS suscitan un problema que tiene que ver con el concepto mismo de los derechos humanos y probablemente con su fundamentación. Se trata de si tienen o no tienen un carácter absoluto. Por lo que a mí respecta, he puesto en duda que tengan ese carácter absoluto en ninguno de los dos sentidos que el calificativo podría tener. No son absolutos «porque pueden entrar en conflicto y, si bien se consideran como «triunfos» a priori frente a otros valores o preferencias, ello no resuelve el problema cuando el conflicto es entre derechos humanos; en tal caso se requiere siempre una ponderación y la satisfacción de un derecho puede tener que ceder total o parcialmente ante la de otro» (HIERRO, 2016: 185). Tampoco son absolutos en el sentido de que sean derechos cuyo enunciado moral es final o definitivo y no requieran compromisos institucionales contingentes para su configuración definitiva como derechos fundamentales. Y, por fin, no todos ellos, pero sí algunos, son derechos absolutos en el sentido de que son derechos erga omnes. Creo que Eusebio FERNÁNDEZ se refiere también a que no son absolutos porque su fundamento y formulación depende del contexto cultural e histórico, y critica aquí con razón que nunca he desarrollado una explicación para pasar de las necesidades humanas a los derechos. Sin duda es cierto, aunque algo parecido he intentado recientemente al explicar cómo se pasa de los derechos morales a los derechos fundamentales siguiendo a Henry SHUE y a James NiCKEL (2016: 186). Ciertamente en esos procesos de positivación aparece claramente esa dimensión cultural e histórica que condiciona el relativismo histórico de los derechos fundamentales aunque, como él mismo subraya, ello no implica el relativismo moral de su fundamento.

Ángeles RÓDENAS lo que apunta es el fracaso del pretendido carácter absoluto de los derechos humanos cuando entran en contradicción ciertos principios institucionales, como se pone de manifiesto en el principio de legalidad, la prisión provisional, los estados de excepción y sitio, la cosa juzgada, etc. Dice ella que estos supuestos minan el carácter absoluto, es decir, la pretensión de que prevalecen siempre sobre demandas colectivas o individuales no constitutivas de derechos. Su argumento sugiere que esto obliga a asumir ciertas tesis del comunitarismo y del consecuencialismo. No creo que obliguen a asumir tesis comunitaristas. Sí obligan, sin embargo, a asumir razones con- 
secuencialistas. Para Ángeles la morfología de los derechos fundamentales es distinta a la de los principios institucionales, los primeros corresponden a los individuos, los segundos a las instituciones. Sugiero que esta diferencia olvida que una buena parte de los principios institucionales, como el principio de legalidad, la jerarquía normativa o la cosa juzgada, no son sino desarrollos institucionales del derecho a la seguridad jurídica de las personas individuales. Probablemente podríamos argumentar la justificación de los estados de excepción en las exigencias de mantener el orden constitucional que garantiza los derechos individuales de las personas, y parece que es por ahí por donde apuntan los matices del constituyente y la doctrina constitucional. En tal caso, basta tomar en consideración las consecuencias de ciertos estados de cosas sobre los propios derechos humanos; no es necesario atribuir una prevalencia a intereses o derechos de entidades transpersonales.

(5) Todavía sobre el fundamento Elena BELTRÁN sugiere que en nuestros textos no queda claro el papel de la dignidad, ni claro su concepto, ni clara su relación con la igualdad. Creo que es muy útil, aunque no la he utilizado, la distinción que ella propone, siguiendo a WALDRON, entre la dignidad como valor y la dignidad como estatus. Efectivamente es una distinción que da sentido al decir que un esclavo conserva su dignidad (valor) pero se ha visto privado de su dignidad (estatus). Lo que no creo - o me encuentro otra vez frente a la incomprensión- es que no haya tratado del concepto de dignidad ni lo haya utilizado para fundamentar los derechos humanos ni lo haya vinculado a la igualdad (afirma BELTRÁn que «no menciona HiERRO la idea de igualdad»). Treinta y tres veces aparece la dignidad en mi último libro y profusamente vinculada a la igualdad; sobre la igualdad trata también una parte del capítulo $\mathrm{V}$ y me ocupé monográficamente de la justicia y la igualdad en Justicia, igualdad y eficiencia (2002). Resumiendo: no sé si ella estaría de acuerdo conmigo en que en la dignidadvalor se ubica el fundamento de los derechos humanos y en la dignidad-estatus se ubica su realización efectiva.

José Luis COLOMER se muestra muy escéptico sobre el valor teórico que la autonomía puede desempeñar en la fundamentación unitaria de los derechos humanos y se une con ello a BOBBiO. No concuerdo con la distinción que COLOMER propone entre la autonomía moral (en sentido kantiano) y en sentido político. Creo, más bien, que la primera es fundamento de la segunda pero, sobre todo ello, no comparto que el variado conjunto de valores (pluralismo, maximización de preferencias, respeto a las minorías...) puedan fungir mejor que la autonomía como fundamento de los derechos humanos. Pienso que es la autonomía la que da sentido a la dignidad-valor y que es ella la que fundamenta la pretensión ideal de que la persona humana es titular de derechos morales básicos para el diseño de un mundo justo, los derechos humanos. Claro es que COLOMER afirma que no existe la conexión que yo defiendo entre libertad negativa y libertad positiva. Aunque no me ofrece argumento alguno en contra.

(6) Pasemos al sujeto. Silvina ÁLVAREZ sostiene que hay que aproximarse al sujeto. Diría yo que eso, hoy en día, constituye o debiera constituir otra elemental doctrina. Y ciertamente es claro que la situación de las mujeres ofrece un amplio panorama de pruebas en favor de esa tesis, que cabría extender a otros grupos humanos discriminados históricamente por motivos moralmente irrelevantes (los homosexuales, los menores de edad, los que tienen ciertas capacidades disminuidas...). Me parece que ello re- 
quiere una reflexión originaria — como ella propone- lo que permitirá alumbrar que no solo arrastramos creencias, costumbres y leyes positivamente discriminatorias, sino que arrastramos también ausencia de creencias, costumbres y leyes que promuevan la igual dignidad de esas personas, es decir que sean negativamente discriminatorias y positivamente igualitarias. Un matiz, quizás: no se trataría tanto de construir la soberanía de las mujeres sino de ubicar a las mujeres en la soberanía.

Pablo De LORA, por su parte, me vuelve a plantear el problema de los derechos de ciertos animales. No lo tengo claro y no me atrevo a sostener una posición cerrada, pero dos ideas me siguen rondando: la primera es que, frente a lo que sostiene $\mathrm{DE}$ LORA, no alcanzo a ver en qué sentido puede asumirse que los muertos, los fetos y los grupos no tienen intereses ni necesidades pero los animales domésticos sí las tienen. En un sentido analógico cabría afirmar que los muertos, los fetos o los grupos las tienen, aun cuando no sean conscientes de que las tienen porque, a diferencia de las personas individuales, no tienen autoconciencia. En ese sentido es en el que se puede predicar lo mismo de los animales o de algunos de ellos. Si lo que situamos como núcleo de la igual dignidad moral de las personas es su autonomía moral, que obviamente requiere la autoconciencia, entonces ni los unos ni los otros la tienen. Cuando DE LORA dice que mi propuesta es ambigua me parece que olvida que, bajo mi punto vista, el prejuicio de la especie tiene un lado negativo, la exclusión de no-personas (sujetos no pertenecientes a la especie humana), exclusión problemática en algunos casos, y tiene un lado positivo, la inclusión de no-personas (sujetos pertenecientes a la especie humana pero privados de autoconciencia), que no parece problemática. He tratado de explicar la diferencia entre el lado positivo y el lado negativo del prejuicio de la especie (HIERRO 2016, capítulo IV) pero no he podido llegar a una conclusión cerrada. Lo más que me he atrevido a concluir es que «los derechos humanos constituyen, por tanto, el contenido de una teoría de la justicia, una teoría que no es moralmente neutra porque implica una determinada concepción de las personas como agentes morales, libres e iguales, pero no constituyen una teoría moral completa; hay multitud de dimensiones del bien que la teoría de los derechos ni abarca ni pretende abarcar. Tenemos obligaciones morales, de las que cabe derivar deberes jurídicos, que no son directamente correlativas de derechos humanos o de derechos morales fundamentales de no-humanos. No debemos maltratar a los animales, no debemos despilfarrar los recursos del planeta, debemos proteger nuestro patrimonio cultural, debemos proteger la diversidad biológica y la diversidad cultural, y así sucesivamente. Para explicar que todo esto es razonable moralmente no necesitamos devaluar el lenguaje de los derechos hasta hacerle perder su sentido y, lo que sería peor, su función en el diseño de un orden político justo» (2016, 156). Una conclusión, quizás, demasiado abierta, o demasiado ambigua (DE LORA); aquí, probablemente, el erizo ha fracasado (Ruiz MigueL).

(7) No tengo muy clara cuál es la respuesta a Manuel ATIENZA cuando pregunta si mi interés por construir una teoría de los derechos humanos que permita ubicar cómodamente en ella a los derechos sociales y el interés de LAPORTA en restringir el catálogo de los derechos humanos tiene algo que ver con nuestra diferencia sobre el imperio de la ley, donde yo introduzco como carácter relevante, para apuntalar el carácter moral de este principio, la legitimidad democrática. Sería fácil responder alegremente que a mí me parece moralmente más relevante la legitimidad en origen y la 
legitimidad en contenido que los aspectos meramente formales del derecho, pero creo que sería una respuesta falsa pues Paco ha señalado que junto a lo que llama la primera estrategia de justificación del derecho, donde sitúa la apelación a la paz y a la certeza, hay que pasar a una segunda, la apelación a la democracia, para terminar en la tercera, la apelación a los derechos humanos, y concluye — como ya vimos- que este último criterio de legitimidad «que no es, por cierto, incompatible con los dos anteriores» es el que se impone en la actualidad «con mayor fuerza» (1993: 73-84; citas de 84). No creo que el haber prestado más atención a un aspecto que a otro suponga desdecir aquella convicción.

Desde mi trabajo de 1982 he tratado repetidamente de formular un concepto de los derechos humanos como derechos subjetivos, en sentido propio y estricto (utilizando la conocida expresión de GROCIO), y en esa tarea he argumentado sobre los derechos cuyo contenido no es libre para el titular, es decir que no son poderes de disposición, como recuerda PÉREZ LuÑo a partir de lo que dije sobre la intimidad de los niños; aunque creo que eso no implica concebir los derechos humanos o algunos de ellos como mandatos de optimización, sino más bien — como PÉREZ LuÑo señala alternativamente- como configuraciones normativas de la seguridad, libertad e igualdad de las personas, como exigencias derivadas de la dignidad moral que nos atribuimos, configuraciones que consisten específicamente en reconocer y proteger ciertas libertades, pretensiones, inmunidades y potestades, que son las formas del derecho subjetivo.

(8) Ricardo GARCÍA MANRIQUE sabe que coincidimos bastante, él y yo, en relación con los derechos sociales. He aprendido mucho de su libro La libertad de todos (2013) aunque no acabo de entender, o de compartir, su empeño en negar el valor autónomo de la igualdad. Me parece evidente que el contenido y las garantías de los derechos humanos dependen de la coyuntura, como señalaba Eusebio FERNÁNDEZ, pero no tengo muy claro que la influencia de la coyuntura coincida necesariamente con la diferencia entre derechos liberales y derechos sociales. Insinuaré dos simples ejemplos. La propiedad privada está considerada un derecho, el derecho, típicamente liberal. La extensión de la propiedad privada de bienes inmuebles a amplias capas de la población no era concebible para los primeros críticos del capitalismo liberal y se veían forzados a imaginar formas de propiedad colectiva, pero tampoco fueron capaces de concebir las enormes limitaciones y cargas que configuran hoy ese tipo de propiedad inmobiliaria. El derecho de asociación obrera, por su parte, es habitualmente considerado un derecho social pero su contenido y garantías son básicamente los mismos del derecho de asociación, un derecho típicamente liberal. Creo, eso sí, que la mejor demostración de que la distinción categórica entre derechos liberales y derechos sociales es errónea se consigue constatando que las supuestas debilidades o limitaciones de los derechos sociales pueden predicarse también de los derechos liberales; como dice Ricardo resumiéndome: «no es que los derechos sociales sean como los derechos liberales, sino que los derechos liberales son como los sociales».

Y pregunta también Ricardo si el mercado no afecta más a los derechos sociales. Tengo dudas, una vez más. Sin ninguna duda el mercado afecta a los derechos humanos, a todos ellos. Y una economía sin mercado también los afecta. Mi impresión es que, de nuevo, la delgada línea roja que pretende separar estas dos categorías de derechos resulta un fracaso. La aparición del mercado afectó profundamente a la 
seguridad y a la libertad, su idea de la libertad, de los profesionales en el siglo XIV. Relata André MAUROIS que «bajo la influencia de los grandes mercaderes, los gremios se transforman. Ya no reina en ellos la igualdad [...] el Rey está ahora bajo el dominio de los comerciantes» (MAUROIS, 1970: 168). Es notoria la influencia del mercado en la aparición de los derechos liberales y no ha de ser menor su influencia en el desarrollo de los derechos sociales. Me resulta difícil, por ello, interpretar la pregunta de Ricardo: ¿Qué significa «afectar»? Me parece que él quiere decir limitar, restringir, condicionar o algo así. El mercado, en efecto, limita, restringe y condiciona tanto los derechos sociales como los derechos liberales. Condiciona más, claro está, la implementación de aquellos derechos cuya satisfacción es más costosa y la de aquellos que han sido formulados más recientemente y tienen, por ello, una configuración institucional menos consolidada.

Pero lo que en este aspecto me ha interesado más ha sido el intento de aclarar el papel que la eficiencia económica, que resulta ser la justificación de la economía de mercado, podría desempeñar en una teoría de la justicia basada en los derechos (Justicia, igualdad y eficiencia, 2002). Me pareció que mientras el pensamiento neoliberal sacralizaba el principio de eficiencia, el pensamiento igualitario lo anatematizaba. He tratado, sin embargo, de formular el lugar que la eficiencia ocupa en una teoría igualitaria de la justicia, de hacer compatible — como señala Ramón VARGAS MACHUCA«la racionalidad económica como parámetro de decisión social [...] y las exigencias de la justicia como teoría de los derechos». Aunque en este punto no he hecho sino desarrollar la teoría de la justicia de RAWLS, ha sido la aportación teórica que más me ha costado formular y la que menos eco ha encontrado. Lo que me hace sospechar que no ha sido muy acertada.

(9) Sin embargo es justo aquí, en la intersección entre el mercado y los derechos humanos donde hoy, se renuevan los problemas de la justicia. La globalización es, sobre todo, el escenario de un mercado situado al margen y por encima de las normas de un estado de derecho. Un mercado en estado de naturaleza. La respuesta cosmopolita, que suscribo y he defendido por escrito, no pretende otra cosa que reconstruir la sociedad internacional como estado de derecho, con los necesarios matices o peculiaridades. Isabel TURÉGANO sostiene con convicción y buenas razones que ello no es posible bajo un diseño liberal igualitario como el que yo defiendo. Afirma que nuestro cosmopolitismo, el mío y el de LAPORTA, es abstracto, que un sentimiento humanista es insuficiente para fundamentarlo y que no he desarrollado la organización estructural que podría realizarlo. Me parece que hay una cierta petición de principio cuando ella nos acusa de ignorar «el peso moral de la variedad de solidaridades que moldean las experiencias personales»y me parece que Isabel tampoco concreta con detalle su esquema estructural, lo que, por otra parte, no es necesariamente la tarea de quienes estamos discutiendo los principios regulativos de una institución. Sin embargo, creo que, a fin de cuentas, coincidimos mucho en lo que ella denomina «elecciones sub-óptimas», como la consolidación de tribunales internacionales, el camino que ya defendió KELSEN, o el desarrollo de las estructuras regionales.

Distinta, más radical diría yo, es la posición de Cristina GARCía PASCUAL que sostiene taxativamente que «debemos partir de la estructura normativa que nos ofrece el derecho internacional» $y$, defendiendo el derecho internacional de los derechos huma- 
nos, concluye que «la comunidad internacional que algunos filósofos de la moral buscan y quieren justificar para que haya un mundo más justo, ya existe, es la comunidad, todavía frágil por supuesto, que nos ofrecen las normas de derecho internacional». Es, desde luego, un respetable pero muy discutible punto de vista. Algunos creemos que la actual situación de las relaciones internacionales, el descontrol político-jurídico del fenómeno globalizador, y, como mínimo, los problemas de la guerra, el hambre o la extrema pobreza y la degradación del medioambiente, nos obligan a proponer pasos más ambiciosos para que el derecho internacional se desarrolle como un orden jurídico efectivo: «un conjunto básico de normas de validez y eficacia universal que sirvan para asegurar [los derechos humanos] por encima de la voluntad de cualquier estructura estatal, supraestatal o subestatal» (HIERRO, 2016: 256). Respondo también con ello, creo, a la segunda pregunta que nos hace Gema MARCILLA.

(10) Tengo la convicción de que la filosofía de los derechos humanos tiene que centrarse cada vez más en este problema. Si no conseguimos que la teoría de la justicia de RAWLS se pueda proyectar en el derecho de las naciones, entonces podemos tirarla tranquilamente a la papelera porque no servirá para nada. Es posible que en otros tiempos la justicia doméstica, la justicia entre los conciudadanos, quedara al margen o fuera de un orden distinto al de la justicia internacional, esto es: la justicia entre los ciudadanos y los extranjeros y la justicia entre sus naciones; haya sido o no haya sido así, hoy esto es imposible. La famosa aldea global es hoy nuestra realidad cotidiana. Y los que todavía en activo tienen (tenéis) que continuar desenvolviendo la reflexión filosófica sobre la justicia, son (sois) los responsables de encontrar respuestas correctas y viables. No os desearía suerte, porque no es cuestión de suerte. Os desearía acierto porque no sé si los estudiosos del derecho, incluidos los filósofos, se dan siempre cuenta de hasta qué punto nuestras reflexiones influyen en la felicidad de las personas. Me atrevo a asegurar que mucho más de lo que cualquiera pueda imaginar.

\section{7. ÚLTIMOS AGRADECIMIENTOS}

He terminado mis comentarios a los comentarios de los que han tenido a bien participar en este diálogo de despedida. Ya os he expresado mi gratitud. Quisiera, no obstante, añadir, primero, un recuerdo a dos compañeros que me brindaron su amistad y nos dejaron antes de tiempo. Me refiero a Albert CALSAMIGLIA y a Jesús GONZÁLEZ AmUCHASTEGUi. Albert falleció en julio de 2000, Jesús en noviembre de 2008. Los dos formaron parte de esta experiencia colectiva que ha sido la renovación de la filosofía del derecho española.

Mi historia académica no es, en verdad, más que una mínima parte de la historia académica de un grupo bien definido de filósofos del derecho españoles que surgió a principios de los años setenta del siglo pasado. Creo que, en esa intrahistoria nuestra, cabe hablar de dos generaciones iniciales: una primera generación - dicho familiarmente, la de nuestros abuelos- de la que formarían parte José Luis LÓPEZ ARANGUREN, Manuel SaCristán, Enrique Tierno Galván, Antonio Truyol y —en lo que a mí respecta- Joaquín RUIZ-GIMÉNEZ; y una segunda generación —la de sus hijos, nuestros padres- de la que forman parte Juan Ramón CAPELLA, Luis GARCía SAN 
Miguel y —en lo que a mí respecta— mi hermano José HierRo, Elías DíaZ y Gregorio PECES-BARBA.

Aquella primera generación tuvo el valor de romper con la ortodoxia imperante en la filosofía del derecho española durante la dictadura, para abrirse al diálogo con el pensamiento liberal, el pensamiento marxista y la filosofía analítica así como a la recuperación del pensamiento español entonces tildado de heterodoxo. La segunda generación culminó esa tarea y, de forma más específica, introdujo en España la orientación positivista-analítica que predominaba entonces en la filosofía del derecho occidental. Ningún esbozo, por breve que sea, de aquella época puede ignorar el mérito de algunos académicos que, procedentes de la ortodoxia oficial, se atrevieron a romper la siniestra disciplina que ejercía Francisco ElíAS DE TEJADA para apoyar a Elías DíAZ; me refiero, claro está, a Nicolás LóPEZ CALERA y José Delgado PinTo. A todos ellos —los viejos maestros, parafraseando a Elías DíAZ— también quiero expresar mi gratitud.

De la tercera generación - la de los nietos, que es la mía- forman parte Joaquín Almoguera, Manuel Atienza, Albert Calsamiglia, Eusebio FernándeZ, Rafael Hernández Marín, Francisco Laporta, Antonio Enrique Pérez LuÑo, Luis Prieto, Miguel Ángel Rodilla, Juan Ruiz MANERo y Alfonso Ruiz Miguel (entre otros y cortando de forma algo arbitraria en los nacidos a comienzos de 1950), y puede calificarse en un sentido muy amplio como la corriente «analítica» de la filosofía del derecho española. Lo que Elías DíAZ y Gregorio PECES-BARBA hicieron en la Universidad Complutense, donde me formé, fue desarrollar los dos polos de interés que RUIZ-GiMÉNEZ atribuía entonces a la disciplina. De un lado, la recuperación del diálogo con el pensamiento filosófico jurídico heterodoxo, principalmente con el pensamiento de la «otra» España. El otro polo de atención era la filosofía del derecho entendida como teoría de la justicia, esto es como teoría del estado y del derecho justos. Hay una gran diferencia entre construir una teoría ontológica sobre la justificación del derecho y del estado que hay (que es lo propio del iusnaturalismo ontológico) y construir una teoría deontológica sobre el derecho y el estado que debe haber (que es lo propio del iusnaturalismo deontológico y de cualquier teoría crítica). En septiembre de 1972 me incorporé al Departamento de Filosofía del Derecho de la Universidad Autónoma de Madrid. Se formó allí, bajo la dirección de Elías DíAz, un equipo bastante compacto. Este equipo puede ser considerado, y así suele serlo, como un grupo más estrictamente analítico, carácter que ha compartido, sobre todo, con las Áreas de Filosofía del Derecho de las universidades de Alicante, Castilla-La Mancha y Pompeu Fabra. Aunque hay, desde luego, muchos otros colegas de orientación cercana en la filosofía del derecho española actual, como acabo de indicar, esos tres núcleos presentan rasgos comunes bastante definidos.

Bajo el enfoque analítico, la filosofía del derecho solo puede tener por objeto el derecho positivo, es decir el mismo derecho que es objeto de las denominadas «ciencias» del derecho y es, al menos en este sentido, positivista. Pero ocurre que el derecho positivo es un fenómeno social normativo y que respecto a los fenómenos normativos cabe adoptar, como respecto a los juegos (que también son fenómenos normativos), dos posiciones diferentes: la del que observa (sea con curiosidad, sea con asombro o sea incluso con desprecio) qué es lo que hacen y lo que dicen que hacen los que juegan; y la del que participa en el juego (sea como jugador, sea como árbitro o sea 
incluso como seguidor partidario de alguno de los jugadores). Estoy convencido de que la filosofía del derecho no es el lugar de los observadores, sino más bien el lugar de quienes - como ha dicho SOPER — reflexionan sobre «un mundo en el cual todos nosotros somos participantes y en el que debemos, ineludiblemente, permanecer como participantes» (1993: 141).

\section{BIBLIOGRAFÍA CITADA}

DíAZ, E., 1980: Sociología y Filosofía del Derecho, Madrid: Taurus.

FERRAJOLI, L., 2012: Un debate sobre el constitucionalismo, Madrid: Doxa-Marcial Pons.

García MANRIQue, R., 2013: La libertad de todos. Una defensa de los derechos sociales, Barcelona: El Viejo Topo.

HART, H. L. A., 1957: «El positivismo jurídico y la separación entre el derecho y la moral», en HART (1962), 1-64.

- 1962: Derecho y Moral. Contribuciones a su análisis, Buenos Aires: Depalma.

HiERro, L. L., 1998: Estado de derecho. Problemas actuales, México: Fontamara.

- 2002a: Justicia, igualdad y eficiencia, Madrid: Centro de Estudios Constitucionales.

- 2002b: «¿Por qué ser positivista?», Doxa. Cuadernos de Filosofía del Derecho, núm. 25, 263 302.

- 2016: Los derechos humanos. Una concepción de la justicia, Madrid: Marcial Pons.

LAPORTA, F. J., 1983: «Sobre el uso del término «libertad» en el lenguaje político», Sistema, núm. 52, 23-43.

— 1985: «El principio de igualdad: introducción a su análisis», Sistema, núm. 67, 3-31.

- 1987: «Sobre el concepto de derechos humanos», Doxa. Cuadernos de Filosofía del Derecho, núm. 4, $23-46$.

- 1990: «Vindicación del observados crítico y aporía del iusnaturalista», Doxa. Cuadernos de Filosofía del Derecho, núm. 8, 131-147.

- 1993: Entre el Derecho y la Moral, México, Fontamara.

- 1994: «Imperio de la ley. Reflexiones sobre un punto de partida de Elías Díaz», Doxa. Cuadernos de Filosofía del Derecho, núm. 15-16, 133-145.

- 2007: El imperio de la ley. Una visión actual, Madrid; Trotta.

Lyons, D., 1984: Ethics and the Rule of Law, Cambridge: Cambridge University Press (Ética y Derecho, Barcelona: Ariel, 1989).

MAUROIS, A., 1970: Historia de Inglaterra, Barcelona: Círculo de Lectores.

Ross, A., 1961: «El concepto de validez y el conflicto entre el positivismo jurídico y el derecho natural», en Ross (1969), 9-32.

- 1969: El concepto de validez y otros ensayos, Buenos Aires: Centro Editor de América Latina. Russell, B., 1968: Ensayos filosóficos, Madrid: Alianza.

SACRISTÁN, M., 1968: Sobre el lugar de la filosofía en los estudios superiores, Barcelona: Nova Terra. SOPER, Ph., 1993: Una teoría del derecho, Madrid: Centro de Estudios Constitucionales. 